\title{
0 apoio pedagógico na formação inicial: perspectivas para 0 bem-estar docente e desenvolvimento profissional
}

\author{
Adelar Aparecido Sampaio* \\ Claus Dieter Stobäus $^{* *}$
}

\section{Resumo}

\begin{abstract}
A partir de vivências de licenciandos e professores iniciantes, o artigo destaca o apoio pedagógico na formação docente, tendo em vista sua relevância para constituição profissional e perspectivas para o bem-estar docente. O estudo longitudinal qualitativo, é parte resultante de pesquisa realizada entre 2012 e 2013, inicialmente, com sessenta e oito potenciais futuros professores de uma instituição privada de ensino superior do Estado do Paraná, e finalizado com cinco docentes iniciantes, com informações coletadas por meio de questionários e entrevistas, tratados com análise de conteúdo. Como resultados no período de formação na licenciatura, destacam-se principalmente insegurança relacional, falta de apoio e interação com sujeitos envolvidos no processo de formação na escola e a necessidade de maior acompanhamento dos docentes no estágio pedagógico. No início na docência, evidencia-se o clima relacional instável entre docentes, falta de ambiente cooperativo entre docentes e ausência de apoio pedagógico ao professor iniciante. Sugere-se a otimização e a institucionalização de apoios aos licenciandos e docentes iniciantes, assim como melhorias das relações entre instituições e sujeitos envolvidos nesse processo formativo.
\end{abstract}

Palavras-chave: Formação inicial. Apoio pedagógico. Licenciandos. Docentes.

\section{Introdução}

$\mathrm{Na}$ formação inicial de professores, se legitima a relevância que o papel dos professores formadores e dos apoios proporcionados aos licenciandos e docentes iniciantes, na promoção de um movimento de (re)construção profissional.

\author{
Recebido: 06/04/2015 - Aprovado: 10/09/2015 \\ http://dx.doi.org/10.5335/rep.v22i2.5225
}

Doutor e Mestre em Educação pela Pontifícia Universidade Católica do Rio Grande do Sul (PUCRS), Brasil. Professor na Unioeste, campus Marechal Cândido Rondon - Paraná - Brasil. Membro dos Grupos de Pesquisa Mal-estar e Bem-estar na Docência da PUCRS e do Grupo de Estudos, Pesquisa e Extensão em Educação Física Escolar da Unioeste. E-mail: adelarsampaio@hotmail.com

** Pós-doutor em Psicologia/Universidad Autónoma de Madrid - Espanha, Doutor em Ciências Humanas/Educação, professor titular nos Cursos de Pós-Graduação em Educação e em Gerontologia Biomédica da PUCRS, Brasil. E-mail: stobaus@pucrs.br 
Nessa perspectiva, inicialmente, gostaríamos de ressaltar, apoiados em Pacheco (1995), que a formação de docentes depende da concepção de ensino, de escola e de currículo preconizada num dado momento e num determinado contexto e ainda das competências e conhecimentos que se reconhecem e se exigem ao professor, mas sobretudo, das oportunidades e dos processos de formação proporcionados aos alunos, potenciais futuros professores, no contexto de formação, quer nas instituições de ensino superior, quer nas escolas. $\mathrm{O}$ mesmo valor, ensejamos ao apoio oferecido ao professor iniciante, por ser uma etapa em que muitos referenciais da profissão são enraizados.

No contexto de formação inicial acadêmica, é reconhecido que o papel do professor formador propicia um movimento de construção e reconstrução profissional no processo de socialização de potenciais futuros professores. É também na licenciatura, segundo André e Hobolt (2013), que os modelos de docência são ressignificados e, muitos deles, construídos. Assim, o trabalho do professor formador possui fundamental importância no aspecto formativo que comporá a futura prática profissional.

No que diz respeito ao estágio de formação, destaca Flores (2010), que a qualidade da orientação, aliada à (in)existência de um clima de apoio e de trabalho em equipe na escola, emergem como fatores determinantes na avaliação deste importante contexto formativo. Na prática, sentimos a necessidade de maior apoio aos licenciandos pelos responsáveis pela sua formação, além de alterações nos enfoques formativos dos conteúdos da formação inicial, frente ao contexto social dinâmico, que, por consequência, gera adversidades ao universo laboral docente.

Na fase inicial da docência, Flores (2010), Mizukami e Nono (2006), Papi (2011) revelam um despreparo de professores iniciantes para enfrentar as realidades da escola e da sala de aula, os quais atribuem, como consequência de uma fraca formação acadêmica, de discrepâncias entre teoria e prática dos professores iniciantes, que evocam sua experiência enquanto alunos para resolver dificuldades confrontadas. A falta de apoio pedagógico orientação aos professores iniciantes nas escolas, é outra situação verificada (SAMPAIO, 2014). Por ser um período considerado como um dos piores da vida profissional docente, de acordo com Huberman (1995), tem se revelado como uma etapa muito importante da história profissional, determinando inclusive seu futuro e sua relação com o trabalho (TARDIFF, 2002). De modo geral, por um lado, o início da carreira constitui um período marcado por crises e o 'choque com a realidade' (ESTEVE,1994; VEENMAN, 1988; JESUS, $1998,2002,2007$ ) representa as dificuldades da nova profissão, podendo incidir em sérias consequências negativas ao desenvolvimento profissional.

Por outro, Jesus (2002), faz referência à formação inicial, num exercício que coloca os potenciais futuros professores à frente de várias situações-problema que a profis- 
são docente pode lhes apresentar, como situações relacionais difíceis, possibilitando a aprendizagem de competências de atuação. Contudo, essa importante fase da carreira profissional, de socialização da profissão, depende das oportunidades de formação e dos processos de interação/inclusão entre agentes envolvidos no contexto escolar, os quais podem oportunizar e otimizar as experiências positivas e auxiliar na superação da influência de experiências iniciais de fracasso (JESUS, 1996; 1998; 2012).

Esses (e outros) entraves tem desafiado a formação docente, haja vista as várias situações de desmotivação à profissão e condições de ensino, muitas vezes precárias, que se revelam como potenciais fontes de estresse excessivo, concorrendo para o desenvolvimento de mal-estar docente (MOSQUERA; STOBÄUS, 1996; MOSQUERA; STOBÄUS, 2000). Além disso, Ramirez e Stobäus (2010), destacam que essa profissão, passa por suas inúmeras dificuldades, principalmente no Brasil, se caracterizando por oferecer poucos incentivos aos professores, sendo a tarefa de trabalho muito exaustiva e solitária.

A partir do exposto, o estudo pretende discutir os apoios pedagógicos no processo de socialização profissional, na consideração que podem propiciar um movimento de construção e reconstrução profissional, posto que, seus benefícios contribuem decisivamente ao desenvolvimento profissional de potenciais futuros professores e docentes em estágio inicial de carreira. Ainda, pretendemos, apresentar vivências pessoais e acadêmicas no processo de formação na licenciatura e sua relação/ interação com responsáveis pela formação docente e, no mesmo sentido, pautar possíveis situações potencializadoras desse processo.

\section{Apoio na formação inicial}

Consideramos que a fase de formação inicial é muitas vezes quase que determinante para o pleno desenvolvimento da motivação para a futura prática docente, podendo incidir inclusive em questões como mal/bem-estar docente, temos verificado que o processo de formação inicial utilizado durante o estágio pedagógico revela-se fundamental na formação dos potenciais futuros professores, pois é a partir dele que os futuros docentes irão adquirir os conhecimentos indispensáveis para sua atuação, sendo um período de desenvolvimento de atitudes, ações, reflexões e o seu próprio projeto profissional.

Segundo Lüdke (2012) os debates atuais sobre a formação de professores têm apontado a necessidade de romper com o modelo tradicional de formação que privilegia em primeiro plano um modelo sólido de formação teórica e de disciplinas pedagógicas de formação e, ao final, as disciplinas de prática de ensino e estágio supervisionado. Segundo a autora, esse modelo ainda comum em muitas univer- 
sidades e centros de formação, é um dos obstáculos à melhoria de preparação de professores em nosso país. Desse modo, postula a necessidade de interligar ensino e pesquisa nos cursos de formação de professores, seja inicial ou continuada, atribuindo ao professor o caráter de pesquisador de sua prática em processo contínuo de reflexão-ação-reflexão.

Para a autora citada, nas licenciaturas, a ideia do profissional reflexivo, tem levado muitos cursos de formação de professores a refletirem e estruturarem seus currículos, no sentido de atribuir à disciplina de estágio supervisionado um caráter mais prático, no qual os futuros professores poderão refletir sobre o contexto real de sua futura atuação profissional.

Segundo Flores (2010) a análise da influência socializadora na formação inicial deve ter em atenção à natureza, o modelo e a estrutura do curso bem como as perspectivas individuais que os licenciandos trazem consigo. O raciocínio que Jesus (2002) destaca, configura a fase de formação inicial durante o estágio acadêmico caracterizando-a como um período fundamental na carreira de qualquer professor, pois: é a fase inicial de prática profissional, sendo esta etapa as experiências mais "marcantes"; é a fase em que os professores sentem maior necessidade de aprendizagem estando mais susceptivos às sugestões e é o único período do percurso profissional em que está institucionalmente previsto acompanhamento e orientação. Por isso, temos envidado estudos nessa perspectiva, pois, uma orientação adequada nesta fase pode contribuir para uma perspectiva de maior confiança, dedicação e motivação relativamente ao resto da carreira.

Concordamos com Flores (2010) quando aborda que a formação dos docentes depende de determinado contexto, das competências que se reconhecem e se exigem ao professor, mas sobretudo, das oportunidades e dos processos de formação proporcionados aos futuros professores nas instituições de ensino superior. Nesse sentido, André e Hobolt (2013) abordam a respeito do início da socialização profissional, a formação inicial deve possibilitar ao futuro professor uma bagagem sólida de conhecimentos, propiciando condições adequadas para a aprendizagem dos alunos, refletindo sobre suas escolhas e decisões, analisando suas ações à luz do entorno em que atua e do contexto mais amplo da educação, para que ao assumir a tarefa educativa, possa desenvolvê-la com rigor e seriedade.

Uma das finalidades da formação inicial é a de preparar os futuros professores para trabalharem em escolas, em contextos de mudança, o que implica num processo de reflexão permanente sobre o papel dos professores e sobre o seu profissionalismo. Nesse contexto, a literatura sublinha a necessidade de repensar a formação de professores na universidade no sentido de responder às exigências e aos desafios cada vez mais complexos que se apresentam às escolas e aos professores (FLORES, 2010). 
Sobre esse enunciado de desafios, Lüdke (2012) confirma uma série de fragilidades, algumas já bastante conhecidas, que no campo de formação inicial de professores, devem ser discutidas e analisadas com mais profundidade. Dentre outras, o descompasso entre a formação teórica fornecida pela universidade e a formação prática de forma contínua e permanente; o despreparo de professores supervisores de estágio; o acompanhamento "mais de perto" do trabalho de orientação ao estagiário no momento de ensaio de um comportamento profissional (podendo ser significativo e inspirador, valendo para o resto de sua carreira); a noção de mediação sobre o trabalho do supervisor, na medida de sua intermediação entre teoria e prática; a desatenção no trato com professores das escolas que recebem os estagiários; a forma de relação com o estagiário (muitas vezes, é mais tratado como objeto do que propriamente como sujeito do seu estágio).

No tocante à fase de iniciação da docência, algumas consequências dos fatos mencionados pela autora supracitada são destacadas por Flores (2010) e revelam um despreparo de professores iniciantes para enfrentar as realidades da escola e da sala de aula, os quais atribuem, como consequência da fraca formação acadêmica. Dentre eles, se evidencia uma discrepância entre teoria e prática dos professores iniciantes, que evocam sua experiência como alunos para resolver dificuldades confrontadas. Acresce a autora sobre a falta de apoio e orientação aos professores iniciantes nas escolas. Essa mesma realidade é apontada também por Nunes e Teixeira (2000) que evidenciaram essa carência nesse aspecto e salientam a grande importância do apoio psicológico aos professores iniciantes. Da mesma forma, o apoio pedagógico no estudo de Sampaio (2014) não se mostrou como prática efetiva na vida docente, justamente no momento em que o professor iniciante se depara com as várias adversidades do contexto escolar. Essa necessidade de apoio aos docentes iniciantes, são ampliadas, pois, ficam, geralmente, com os piores horários e com as turmas mais difíceis, conforme destacam Cavaco (1991), Esteve (1992) e Veenman (1988). Além disso, o sistema de distribuição de aulas obriga à deslocação do professor de escola para escola, de localidade para localidade, o que dificulta a sua inserção no meio profissional e a estabilidade da sua vida familiar e social (JESUS; SANTOS, 2004).

No que diz respeito ao apoio aos licenciandos estagiários, Roldão (2007) afirma que a escola básica também é espaço de formação do profissional da educação, embora não se possa afirmar que as escolas e seus profissionais tenham esse entendimento. No caso do trabalho do pedagogo escolar, o estágio requer o acompanhamento, na escola, desse profissional atuando na gestão dos processos pedagógicos escolares. Ressaltamos ainda, apoiados em Imbernón (2011), a importância de construir um contexto interativo, de valorização do trabalho dos colegas de 
profissão, promotor da discussão e da reflexão entre os pares. Para o autor, ainda é persistente na escola, infelizmente, um ambiente pouco cooperativo, em que os professores não costumam trocar ideias com seus colegas, discutir novas práticas, buscar a ampliação dos saberes que lhes permitam desenvolver maior capacidade de confrontação entre teoria e prática e maior competência profissional.

Nessa necessidade de se reconhecer o papel da escola como espaço de formação do futuro profissional, para Lüdke e Rodrigues (2010) existem algumas dificuldades e limites dessa proposta, destacando a falta de tempo adequado para a realização dos estágios (para acompanhamento dos estudantes, discussão, planejamento e avaliação das atividades). Para as autoras, os maiores desafios se referem à necessidade de preparação do professor da escola básica para receber, acompanhar e orientar os estagiários, além da própria necessidade de revisão das condições de trabalho nas escolas, de modo que os professores pudessem ser liberados de parte de suas atividades diárias para se dedicar à formação dos futuros docentes, o que implica em investimento financeiro por parte das mantenedoras. As autoras acrescentam, também, a necessidade da própria preparação do supervisor da universidade responsável pelos estágios.

No estudo sobre a relação escola e universidade de Mira e Romanowski (2012), os dados obtidos evidenciam a fragilidade dessa relação. Segundo as autoras, a maior parte das dificuldades refere-se a duas questões principais: a ausência da institucionalização dos estágios, dificultando o estabelecimento de parcerias mais efetivas com as escolas e as possibilidades de acompanhamento implantadas em função das condições institucionais estabelecidas, tais como: o número de estudantes por professor para acompanhamento; o acesso/deslocamento às escolas-campo de estágio; o acolhimento e o acompanhamento dos estagiários pelas escolas e seus profissionais, principalmente nos cursos noturnos; a demanda de trabalho dos profissionais das escolas e das instituições de ensino superior. Esses entraves na formação ainda soam como desafio a ser enfrentado.

Essas evidências apontadas, em nosso entender, suscitam da formação docente, uma nova forma de abordagem no sentido de responder satisfatoriamente às demandas originárias da dinâmica social, municiando os docentes de estratégias para fazer frente às demandas em diversas situações do contexto educativo. Salientamos ainda, o que temos verificado em nossas pesquisas, as adversidades e diversas demandas do universo docente que concorrem para o desenvolvimento de mal/bem-estar docente. Sobre essas questões, Mosquera e Stobäus (1996, 2000) afirmam a existência de um contínuo acirramento desse problema desgastando a docência ante as insatisfações dos professores, os descontentamento dos alunos, improdutividade do conhecimento e ainda a desconfiança social. Os autores salien- 
tam ainda que, embora existam causas econômicas, políticas, sociais e profissionais, quase nada é apontado sobre a pessoa do docente, suas inquietações, interesses, valores e expectativas, com menor eficácia docente, por conta da diminuição da motivação docente.

A difícil realidade apontada pelos autores condiz com as considerações de Jesus (2002), sobre o processo de entrada no mercado de trabalho docente a constatação provável, em relação aos professores que abandonam a profissão no início da carreira, é de que esses teriam potencial para serem eficazes se tivessem sido encorajados, apoiados e preparados durante os primeiros anos de ensino, na transição da formação inicial para a prática profissional. A esse respeito, o autor também enfatiza que, no início de carreira, podem acontecer três configurações motivacionais, podendo os docentes restarem: indiferentes, satisfeitos ou desiludidos. Essa última situação acontece com muitos professores que ingressam motivados na profissão docente, mas que começam a ficar desmotivados em virtude do 'choque de realidade', o que quer dizer, o encontro com a realidade da escola.

Qualquer ação educativa, no caso de intervenção junto aos professores em início de carreira, de acordo com Mosquera e Stobäus (1984) é importante que as modalidades de suporte desencadeadas pelo orientador e seus colegas, resultem que o "choque com a realidade", seja superado e a profissão docente possa ser vivida com motivação e entusiasmo, constituindo um meio de realização pessoal. Para prevenir o "choque com a realidade", fator já descrito por Esteve (1994) como um dos principais motivos para a desmotivação e forte contribuinte para o mal-estar docente em estágio inicial, salientamos para a importância de envidar esforços no sentido de promover e otimizar ações específicas no contexto formativo nos cursos de Licenciatura, de forma adaptada, pois, segundo Jesus (2007) é preferível um "choque com a perspectiva", no sentido de fornecer um panorama mais realista da profissão docente, conjugando esse modelo com uma perspectiva otimista, salientando também os aspectos positivos, os bons exemplos e as possíveis experiências agradáveis da docência.

\section{0 professor formador na licenciatura}

Inicialmente, queremos destacar, que a relação professor formador e licenciando, apesar de resguardar características gerais, por ser dinâmica e envolver pessoas, cada uma com suas subjetividades, se estabelecerá em níveis diferenciados. Nesse sentido, é importante destacar o papel do professor formador na constituição de um professor mais saudável, como apontam Mosquera e Stobäus (2004), que tenha melhores relações interpessoais, e que, ao mesmo tempo, conduza seus 
educandos (e a ele próprio) à autorrealização, pressupondo o chegar a ser alguém e realizar algo que seja relevante para nós mesmos e os demais. Para isso, os autores sinalizam a importância do desenvolvimento da sensibilidade, intuição e refinamento dos sentimentos. Vale registrar as considerações de Grillo, que destaca "o processo formativo é por natureza social, pois os professores se constituem como tal em atividades interpessoais, seja em seu período de preparação, seja ao longo da carreira" (2004, p. 72).

Segundo Jesus (1998) o apoio do orientador pode ocorrer no plano comportamental (desenvolvimento de competências profissionais), cognitivo (adequadas crenças, expectativas e atribuições) e emocional (suporte social), evidenciando as qualidades e os aspectos positivos da atuação do estagiário, preparando-o para a construção do seu estilo pessoal de ensino, durante o processo de ensino e aprendizagem (relação pedagógica e 'pedagogia do imprevisível'), para além do antes (planificação) e do depois (avaliação) desse processo. Para Grillo (2004), o papel docente engloba uma diversidade de ações desenvolvidas além do espaço da sala de aula, voltadas prioritariamente à formação de futuros profissionais, sustentadas pelos próprios conhecimentos e saberes. Nesse sentido, encontramos em Zabalza (2004) a diferenciação de três categorias, que não são excludentes e que podem caracterizar qualitativamente o papel docente a ser desempenhado pautado na: dimensão pessoal (aspectos importantes no mundo da docência, como o envolvimento e compromisso pessoal, a constituição dos ciclos de vida, situações de mal-estar paralelas e consequentes ao exercício profissional); a dimensão administrativa (condições contratuais e operacionalização de estratégias de permanência qualitativa do vínculo institucional); e, a dimensão profissional (componentes essenciais que definem essa profissão de professor como exigências e/ou expectativas quanto à atuação, dilemas inerentes e necessidades formativas, dentre outras). Predominantemente, para Grillo (2004), a relação que se estabelece entre professor e aluno possui sempre um caráter de reciprocidade. De forma implícita nessa relação, há predominância de apoio afetivo, técnico ou cognitivo e de laços solidários, prazerosos ou desafiadores.

Independentemente da forma de guiar os alunos durante o processo de socialização profissional, Azevedo e Andrade (2010) acreditam que os professores formadores podem reconstruir os saberes de orientação/formação e que essa relação não deve ser fechada e única, mas deve se diferenciar mediante as necessidades observadas e sentidas nos alunos. Assim, a homogenização e o enquadramento das ações dos professores formadores devem ser evitados e, como núcleo dessa ação, a diversidade, a variabilidade e a profundidade nos encaminhamentos propostos aos alunos devem ser a meta docente. Baseados nessa ideia, os autores sugerem uma 
relação paralela entre o estilo inovador de orientar e a tríade professor formador-aluno-contextos formativos, refletindo e redimensionando nos próprios cursos de formação. Esse modelo de formação de professores, para as autoras, pautado na racionalidade emancipatória e reflexiva, potencializa uma formação que conduz o profissional da educação e futuro professor a uma prática docente e pré-profissional de atuação e reflexão permanente, porque reconhece que a história, as tradições e os costumes da cultura escolar e social entrelaçam-se com as práticas educacionais. Nesse sentido, a mediação docente dos professores formadores durante os processos de formação, por meio do movimento dialético e reflexivo, traria em si a preocupação de operar transformações contextuais, além de investir nas repercussões do processo vivido.

Sobre os modelos de formação, Esteve (1994) colabora apontando a distinção entre o "modelo normativo" e o "modelo descritivo" na análise do processo de formação de professores. Para o autor, o modelo normativo pressupõe que a eficácia do ensino resulta de certos traços de personalidade, comportamentos específicos do professor ou de certos métodos pedagógico-didáticos por esse utilizados. Esse modelo considera que a formação deve incidir no treino de comportamentos e competências características do "bom professor" ou do "professor eficaz", pretendendo-se que todos os professores tenham essas características em número máximo (JESUS, 1996, 2012; ESTEVE, 1994).

Além disso, Esteve (1994) verifica que a formação segundo modelos normativos leva o professor a iniciar a sua prática profissional em função do estereótipo do “professor ideal”, passando rapidamente da idealização inicial à decepção. Esses modelos para Jesus (1996) colocam em cada professor toda a responsabilidade pela sua eficácia profissional, ao estabelecerem uma relação direta entre o comportamento ou a personalidade do professor e o seu êxito na docência. Desse modo, se o professor não obtém êxito é porque não tem jeito, não serve ou não é bom professor.

Essa contínua comparação que cada professor estabelece entre a sua atuação e/ou qualidades pessoais e comportamentos e/ou características ideais, segundo Jesus $(1996 ; 2012)$, pode levar a uma desvalorização de si próprio, se não atinge ou percepciona em si esses comportamentos e características ideais, o que se traduz na percepção de incompetência e na falta de empenhamento profissional. Além disso, complementa o autor, se o professor percepciona fracassos no seu desempenho profissional, essa comparação pode também levar a uma desvalorização da formação, como forma de preservar a autoestima. No entanto, embora receba críticas de vários níveis e por diversos autores, o modelo normativo ainda parece predominar na formação de professores. 
A substituição do modelo normativo pelo descritivo é considerada por Esteve (1994) como uma das principais linhas de atuação na formação inicial de professores, de forma a prevenir o mal-estar docente. Ao contrário do modelo normativo, o modelo descritivo considera que a formação deve tentar contribuir para que o sujeito consiga identificar e descrever o seu funcionamento no confronto com as situações e aperfeiçoar as suas competências, numa perspectiva de aprendizagem constante, reconhecendo as suas limitações, mas nunca se colocando a si mesmo em causa (ESTEVE, 1994).

Em substituição ao modelo normativo, Jesus (1996; 2012) vê complementariedade nos modelos humanista e descritivo, sendo a principal diferença entre eles, a ênfase que o modelo humanista coloca nos pressupostos e objetivos da formação, enquanto o modelo descritivo salienta as estratégias de formação que podem permitir atingir esses objetivos. E, em alternativa ao modelo normativo e ao modelo descritivo, proposto apenas para o período de formação inicial, Jesus (1996; 2012) destaca o modelo relacional, o qual pretende servir de enquadramento a todo o processo de formação educacional, traduzindo-se em diferentes estratégias de formação, seja na inicial ou na contínua. Para o autor, o principal objetivo de um modelo relacional de formação centra-se na preparação do professor ou do potencial professor, conforme termo que prefere adotar nesse caso do licenciando em formação, para que se realize na profissão docente, alcançando os seus objetivos, e não que se limite a adaptar-se, prescindindo dos seus objetivos e do seu estilo pessoal, entrando na rotina e fazendo o mínimo possível.

Nesse sentido, a formação e a atuação do docente formador, deve potencializar o conhecimento sobre a realidade contextual do universo docente e desenvolver competências de descrição do próprio licenciando/docente, em face de situações contextuais, ajudando-o no desenvolvimento de competências de ação. Nessa perspectiva, a atuação do docente formador pode constituir-se numa situação de formação, importante para a aprendizagem significativa para o exercício da docência.

Para além das expectativas de modelos de formação, a importância do professor formador na constituição do docente, passa por diversas formas de atuação, das quais a relacional pode estreitar os laços de aprendizagens aos futuros professores. Como fundamental nessa relação, conforme salienta Flores (2010), é promover espaços para explicitar crenças e representações que os candidatos a professor trazem consigo para os cursos de formação inicial no sentido de questioná-los de modo fundamentado e consistente; enfatizar a natureza problemática e complexa do ensino, fomentando a reflexão e a investigação sobre a prática docente e sobre os valores e propósitos que lhe estão subjacentes como eixos norteadores da formação; problematizar o processo de tornar-se professor no sentido de uma (re)construção 
pessoal do conhecimento sobre o ensino (que contrarie a lógica prescritiva e procedimental ainda prevalecente nalgumas concepções de alunos - futuros professores) com implicações para a (trans)formação da identidade profissional; reconhecer que a formação inicial é incompleta e que se inscreve num processo formativo mais longo, integrado e holístico (incluindo o período de indução) numa lógica de desenvolvimento profissional e numa perspectiva de aprendizagem ao longo da vida; e, clarificar a filosofia subjacente a determinado projeto de formação em que a reflexão e a investigação se assumam como elementos estruturantes.

\section{Metodologia do estudo}

O empreendimento de pesquisa caracteriza-se por um estudo exploratório-descritivo na abordagem qualitativa e de natureza longitudinal e foi desenvolvido em duas etapas, sendo a primeira, no período final da formação pedagógica entre os dias 5 e 8 de novembro de 2012, realizada com licenciandos do último período dos cursos de Pedagogia, Letras e Educação Física de uma instituição privada do Estado do Paraná.

Os sujeitos participantes dessa primeira etapa constituíram a amostra de 68 alunos, sendo 53 são do sexo feminino e 15 do sexo masculino, com idades compreendidas entre 19 e 46 anos de idade, todos cursando o último ano dos seus respectivos cursos e ainda não haviam exercido docência como professor titular. Como instrumento de coleta de dados da primeira etapa, foi utilizado questionário com questões abertas, sendo a identificação desses, realizada pelos números de "1" a "68" antecedido da letra S (de sujeito).

Na segunda fase, em 2013, já com os sujeitos no início da carreira docente, optamos pela entrevista como instrumento de coleta de dados, realizadas no segundo semestre letivo, com a participação de 5 (cinco) docentes. A escolha desses sujeitos foi baseada a partir de suas manifestações sobre entrada no mercado de trabalho e da disponibilidade desses na continuidade da pesquisa. Tanto as entrevistas como os questionários com questões abertas foram tratados com análise de conteúdo na proposta de Bardin (2010).

O estudo, que é parte resultante de tese de doutoramento, foi aprovado pela Comissão Científica, em 2012, sob número 079/2012 e pelo Comitê de Ética da PUCRS - CEP - sob número 09470612.7.0000.5336, contando com o Termo de Consentimento Livre e Esclarecido TCLE e respeitando os aspectos éticos de pesquisas com pessoas. 


\section{Resultados}

Em cumprimento dos objetivos traçados inicialmente no artigo, apresentamos as informações captadas nos relatos dos licenciandos e docentes iniciantes relativas às interações e citações que dizem respeito ao professor formador e aos apoios recebidos e/ou citados nas esferas de formação acadêmica e de docência inicial.

$\mathrm{Na}$ primeira etapa com licenciandos, emergiram relatos dos sujeitos sobre o importante o apoio dos professores e dos próprios colegas na formação acadêmica, num movimento que otimizou o processo de orientação e na busca de soluções para a superação de adversidades contextuais, como destacam: "As conversas com professores e coordenador do curso me auxiliaram muito [...]" S63; "Quando encontrei dificuldades procurei os professores ou os alunos colegas que sempre ajudaram" S38; "Nos estágios estou sempre em contato com a professora orientadora e isso acaba facilitando muito" S31; "As trocas de experiências entre colegas formandos ajudam muito nessa fase" S30; Lembramos Jesus (2002) referindo-se ao estágio acadêmico como o único período da formação docente em que está previsto, institucionalmente, um acompanhamento pedagógico. Nesse sentido, ressalta o autor, que uma boa orientação nesse estágio permitirá ao licenciando boas perspectivas de atuação e sucesso para o resto da carreira.

Como demanda percebida foi citada a necessidade de maior acompanhamento dos docentes no estágio pedagógico com ações que poderiam ser mais vantajosas para a sua preparação profissional, dos quais destacamos: "Acredito que seria melhor se tivesse uma preparação maior, talvez com maior acompanhamento dos nossos docentes" S31; "Se tivesse um acompanhamento mais de perto nos nossos estágios" S55.

De acordo com Flores (2010), os formadores de professores precisam repensar o seu papel (e o modo como trabalham) à luz dos desafios da sociedade do conhecimento e da aprendizagem em que os professores têm agora de trabalhar. Complementa a autora, se queremos nas escolas professores que reflitam sobre as suas práticas (e sobre os propósitos e valores que lhes estão subjacentes), então os cursos de formação (inicial, mas também contínua) têm de ser organizados em função dessa realidade, colocando de lado processos e práticas de formação dominados, em muitos casos, por modelos tradicionais, escolarizados e baseados numa racionalidade técnica. Conforme a autora, um ensino de qualidade exige professores de qualidade, que sejam conhecedores, que demonstrem destrezas para enfrentar a complexidade e a mudança inerentes à docência, mas também que estejam comprometidos no ensino e na aprendizagem ao longo da sua carreira. 
Em relação à percepção de eficácia quanto à formação para os estágios, consideramos que é variável de aluno para aluno. Por exemplo, na percepção de $\mathbf{S 2 4}$, houve uma boa orientação para a prática dos estágios, conforme cita "Os estágios são sempre bem explicados e orientados”. Acreditamos que o nível de dificuldade e percepção de necessidade de mais apoio é muito variável e depende de fatores, como as experiências prévias dos alunos, capacidade de relação das informações recebidas dos professores formadores com o contexto em que o aluno está se inserindo, do próprio interesse e desenvolvimento estudantil, dentre outros.

Para André e Hobolt (2013), é em contato com os professores formadores que os estudantes podem desmistificar e ressignificar determinadas informações e conhecimentos adquiridos em sua trajetória de alunos. No entanto, evidenciamos o desafio de discutir mais sobre os dados coletados e compará-los com outros achados, de outros contextos e as possibilidades de melhorarem a qualidade do seu trabalho. Acreditamos que são questões que remetem a um olhar sobre o contexto institucional e para as políticas governamentais para que propiciem melhores condições de trabalho aos professores formadores. Segundo André e Hobolt (2013, p. 195), "Estes não podem ser culpabilizados como os únicos responsáveis pela falta de qualidade dos cursos e pela fragilidade da formação dos docentes".

Outra importante situação, segundo Lüdke (2010), é o envolvimento dos professores que atuam na universidade e os que atuam na educação básica. Desse modo, os estágios poderiam ser mais próximos da realidade e das necessidades de formação dos estudantes, o que agregaria na formação docente, trazendo benefícios para ambas instituições, com repercussões positivas de suporte ao potencial professor.

Destacamos ainda citações sobre o apoio dos professores das escolas, como descrevem S39: "Poderia ter mais apoio dos professores nas escolas"; S41: "As escolas poderiam ser mais receptivas aos estagiários"; $\mathbf{S 5 2}$ e S68: "Com maior apoio das escolas no sentido da realização do estágio". Ainda sobre as potenciais fontes de mal-estar relacionadas do contexto formativo relacionadas no estudo, foram indicadas as dificuldades nas relações com professores das escolas, como citam $\mathbf{S 6 8}$, especificamente à atividade de estágio na escola: "Nos estágios, a convivência com professores que já atuam a tempo na escola é conflituosa" S62; "Alguns professores não te apoiam, às vezes até dificultam nosso estágio, não estão nem aí [...]" S62; "Na escola foi difícil, pois muitos professores não valorizam o estagiário" S28; "Existem algumas pessoas nas escolas que não estão nem aí para tua formação" S22.

Consideramos importante destacar as divergências que chamamos desse momento de choque de geração, interesses, motivação, ou ainda, falta de ética profissional, os quais são verificados nas falas dos sujeitos, quando evidenciam 
dificuldades na relação com professores mais experientes das escolas. A esse respeito, Huberman (1989) destaca sobre os ciclos de vida docente, os quais retratam, conforme tempo de serviço e motivação à prática educativa, diferentes níveis, que distinguem entre professores mais e menos motivados em cada fase da carreira docente, tendo em conta as diferenças individuais no percurso profissional dos professores. De outra perspectiva, é importante que se lembre dos professores, não retirando sua função de colaborador à formação do estagiário, a existente situação do contexto atual sobre as demandas que acrescem a eles nas escolas, de forma que, muitas vezes, não conseguem atender as necessidades de apoio a seus próprios alunos. Ainda é importante que se leve em consideração o contexto envolvido em cada situação vivenciada.

De qualquer modo, as ações dos professores colaboradores das escolas e própria escola é parte integrante da formação dos futuros docentes, cabendo a ela interagir e participar da melhor forma frente às necessidades de práticas de estágios.

Ressaltamos a grande importância nessa etapa de formação da relação de apoios entre as instituições Universidade e Escola. A relação dessas duas instituições é algo de reflexões, pois delas devem decorrem ações formativas que devem caminhar em sentido de mão dupla. De forma recíproca, as duas instituições desempenham papel importante na formação docente, de forma que a Escola deveria trazer para o campo de discussões as demandas que se apresentam no contexto escolar, assim como, a Universidade contribuir para a formação permanente e continuada da docência, firmada em novos conhecimentos originados de estudos e experiências do próprio campo de formação docente. Nesse sentido, Escola e Universidade exercem papéis extremementes importantes para a sociedade.

Já como docentes iniciantes, os professores evidenciam uma evolução das relações interpessoais a partir do início da docência, com observações de reações de menor abertura à interação com professores mais experientes no início do convívio, à melhor relação com o passar do tempo, conforme explicitam: "Acredito que com os colegas a gente está interagindo melhor. Quando comecei foi mais difícil. Hoje a gente conversa, a gente troca informações, atividades [...]" S23; "No início foi difícil, por que parece que me viam aqui na escola como uma ameaça, coisa assim de tirar aulas e conseguir uma classificação melhor no teste seletivo. Aos poucos você vai conseguindo conquistar mais a confiança dos colegas" S39. É perceptível a relação de maior entrosamento quando há trabalhos em conjunto, de forma interdisciplinar, como destaca $\mathbf{S 2 8}$ "A interação é melhor quando gente tem alguma atividade em conjunto, principalmente”.

Esta assunção pode estar ligada à inclinação dos novos docentes ao desenvolvimento de sua função baseada no espírito de equipe, com vistas a uma maior ne- 
cessidade de envolver-se no grupo, trocando experiências, assim como denota uma maior necessidade desse tipo de convivência, haja vista sua menor experiência.

Porém, como dificuldade localizada, houve relatos sobre a desunião de professores e a falta de integração com os professores iniciantes: "Eu percebi que professores da minha disciplina era cada um na sua, não existia muita cooperação, conversas entre si" S28. O mesmo sujeito ainda destaca sua percepção sobre a concorrência que existe entre professores de mesma área, devido a seleções de docentes, como relata: "Eu percebia que existia uma concorrência entre meus colegas e muitas vezes não eram compartilhadas algumas informações comigo [...] Dentro da escola existem algumas desavenças entre professores, embora eu não tenha problemas com outros professores, nem com a escola, no fundo acaba influenciando a gente".

Percebemos também nos relatos dos sujeitos o rótulo de que ainda não são capazes de exercer a docência, o que se caracteriza como falta de confiança, como destacam o sentimento de rejeição e pouca confiança por parte de professores mais experientes: "Eu acho que deveria ter um pouco mais de respeito por parte de alguns professores. É uma falta de confiança que eu sinto" S37; "Muitas vezes pensam que você não é capaz, foi o que senti nesse início [...] é difícil mudar a cabeça das pessoas, para uma convivência melhor." S39; "Encontrei apoio das pedagogas que por um lado ajudavam e por outro vigiavam, por que senti que elas mesmo tinham receio de me colocar numa sala de aula com 40 alunos, sendo uma professora recém-formada, totalmente sem experiência" S37.

A formação docente é alvo de estudos de Mosquera e Stobäus (2006) numa perspectiva de otimizar melhores relações interpessoais na Educação. Os autores nos lembram que, quanto maior o número de pessoas que lidamos em determinado contexto, maior será a dificuldade. Vemos num primeiro momento, que a tarefa é muito difícil. No entanto, cremos que o ambiente escolar somente terá mudanças significativas nas questões relacionais, a partir do momento que se trabalhe numa perspectiva de melhorar e ampliar a consciência da pessoa, numa perspectiva de otimização das relações interpessoais de forma saudável, conforme nos esclarecem os autores citados.

Lembramos que, atualmente, ser professor, envolve muito mais do que a formação sobre a prática pedagógica. Cremos que as vivências pregressas da vida pessoal também concorrem para essa constituição profissional. Para Nóvoa, a bagagem essencial de um professor adquire-se na escola, através da experiência e da reflexão sobre a experiência. Para o autor, "O que dá sentido à formação é o diálogo entre os professores, a análise rigorosa das práticas e a procura coletiva das melhores formas de agir" (2013, p. 233). 
Para os sujeitos, a falta de apoio pedagógico aos docentes iniciantes por parte dos demais profissionais da escola, poderia proporcionar maior eficácia profissional, conforme relatam os sujeitos que presenciaram tais situações: "Quando entrei na escola [...], eles mal falaram comigo, entrei na sala e foi difícil, você não tem aquele suporte, nem me acompanharam" S37; "Vejo que o apoio da escola é essencial para nós que estamos iniciando" S32; "Foi bem difícil no início, tive que me virar sozinha" S23. "Tive oportunidade de trabalhar em outra escola e foi bem diferente. Lá eu tive mais apoio, não me senti sozinha" S28. "Aqui nessa escola que eu trabalho [...] sempre tive esse apoio desde o início. Mas em outra escola que também tenho aula, as coisas são bem diferentes. A gente tem que se virar como pode. Existe sempre um clima de disputa entre os professores" S39; "Só encontrei apoio de uma pessoa na escola que era minha colega na faculdade. Os demais todos te olham de uma forma diferente" $\mathbf{S 3 2}$.

A respeito do apoio dos colegas professores no âmbito da docência em seu estágio inicial, Jesus (2007) evidencia esse aspecto como fundamental no início da prática profissional. Entre sugestões mais aprazíveis, para Veenman (1988) estariam: o fornecimento de informações sobre as condições de trabalho e as regras da escola; visitas à escola antes do início das aulas; reuniões com os supervisores; conferências sobre tópicos específicos; oportunidades para observar aulas de colegas, ensino em equipe, encontros e reuniões com professores mais experientes.

No mesmo sentido, Cavacco (1991) enfatiza como um dos aspectos mais referidos na literatura, o acolhimento dos novos docentes pelos outros professores da escola. Para o autor, muitos professores em início de carreira referem sentir-se melhor junto dos alunos do que dos próprios colegas de profissão, tendo em conta a proximidade de idade. De qualquer forma, pensamos que seria mais saudável para 0 entrosamento entre docentes, um processo de aproximação, pelo fato de que a função docente pode render melhores resultados num plano de trabalho coletivo. Já Nóvoa (2013) acredita que para ensinar bem não basta dominar um determinado tipo de conhecimento e não depende apenas da boa vontade de cada professor, sendo fundamental compreendê-lo na sua matriz histórica, científica e social. Para o autor, a formação de docentes deverá estar baseada em dois princípios - reflexão e compreensão, dependendo também do modo de organização das escolas. Nesse sentido, sugere que os colegas mais experientes e mais competentes devem exercer um papel de acompanhamento e de supervisão, devendo os professores reunir-se regularmente para analisar os problemas pedagógicos. Complementa ainda, que a colegialidade, a partilha e as culturas colaborativas não se impõem por via administrativa ou por decisão superior, sendo importante a consolidação de parcerias no interior e no exterior do mundo profissional e para reforçar o trabalho cooperativo dos professores. 
Ainda podemos considerar a realidade escolar como pouco cooperativa, citando uma cultura individualista, conforme destaca Imbernón (2011), a importância de construir um contexto interativo, de valorização do trabalho dos colegas de profissão, promotor da discussão e a reflexão entre os pares. Para o autor, ainda é persistente na escola, infelizmente, um ambiente pouco cooperativo, onde os professores não costumam trocar ideias com seus colegas, discutir novas práticas, buscar a ampliação dos saberes que lhes permitam desenvolver maior capacidade de confrontação entre teoria e prática e maior competência profissional.

Os professores iniciantes citam a falta de apoio psicológico ao professor, como dizem: "Os problemas acontecem e muitas vezes não temos a quem recorrer [...] isso vai acumulando [...] S28; "Precisaria de psicólogo para nos ajudar a saber como reagir nessas situações" S23; Muitas vezes, se servem de auxílio de amigos e colegas mais próximos quando se deparam com situações mais difíceis, como exemplo, citamos: "Busco sempre o apoio da coordenação, mas não é sempre que isso é possível” S39. Essa situação é recorrente e Nunes e Teixeira (2000) já nos alertavam sobre essa carência em âmbito escolar para a necessidade de apoio psicológico aos professores. Na mesma direção, o estudo de Sampaio (2014) também verifica a falta de apoio pedagógico aos professores iniciantes, nessa marcante fase da carreira profissional.

\section{Considerações prévias}

Este estudo nos propiciou refletir e reconhecer primeiramente a existência de várias interações do contexto formativo que incidem no processo de formação acadêmica/profissional e, consequentemente, no processo de socialização profissional.

No que diz respeito aos apoios aos licenciandos/docentes iniciantes, percebemos que essas vivências do contexto formativo, em específico, as destacadas no presente estudo, de certa forma, antecipam um sentimento de desmotivação sobre a profissão docente, podendo incidir como consequência negativa para o desenvolvimento profissional docente. $\mathrm{O}$ fato de verificarmos um contexto pouco cooperativo, mostram evidências que podem desencadear o comportamento de isolamento docente, o que na literatura da área é descrito como consequência de mal-estar docente.

As evidências destacadas ressaltam a necessidade de incrementar investimentos nas modalidades de suporte aos licenciandos/docentes. Nesse sentido, proporíamos o desenvolvimento de programas de apoios, tanto na Escola, quanto na Universidade, incrementando ações entre esses dois contextos, a fim de que ambos possam reciprocamente, trocar informações, formar-se, atualizar-se, enfim, 
que possam caminhar juntos, numa relação mais convergente e colaborativa ao processo de formação docente, num sentido mais amplo: na fase inicial de formação acadêmica, socialização profissional e na formação continuada do docente. Da mesma forma, a promoção de encontros de formação entre licenciandos e seus orientadores/supervisores de estágios e professores das escolas, no sentido de propiciar melhores condições para uma inter-relação mais saudável, pautados no espírito de cooperação entre os envolvidos nesse contexto de formação docente;

No contexto inicial de formação docente, a vivência com a escola desde a formação acadêmica, coloca o professor frente a uma série de contrastes e dificuldades contextuais do universo laboral. É nessa direção que, reafirmamos a necessidade de avaliar e pensar a formação dos professores, adequando seu enfoque de forma convergente às necessidades formativas. Mesmo reconhecendo que a realidade pesquisada, não seja a presente em todos os contextos, nosso entendimento, é da necessidade de se repensar a formação inicial na perspectiva de desenvolvimento profissional para o bem-estar do professor, no sentido do incremento e suporte para o exercício da docência.

Desse modo, ainda proporíamos desencadear ações interventivas no plano sociopolítico para atrair potenciais professores com maior valorização profissional e imagem social da profissão, além de fomentar melhores qualificações no sentido continuado, manter os melhores professores nessa profissão, incentivar o seu desenvolvimento profissional, institucionalizar apoio pedagógico e psicológico aos docentes iniciantes e promover a interação desses com o coletivo docente com vistas a desencadear um ambiente de cooperação. Pela carência de estruturas institucionais de apoio ao professor no início da docência, acreditamos que intervenções futuras, nesse sentido, podem permitir um quadro de maior motivação e bem-estar na docência. Caso contrário, há uma grande possibilidade de não encontrar-se na profissão, não vendo resultados positivos em suas tarefas, podendo culminar com a desistência do magistério ou a sua continuidade em estado de crescente mal-estar.

Por fim, reconhecemos a necessidade de realizar estudos mais exaustivos, ampliando os horizontes e avaliando outros contextos de formação inicial docente, objetivando analisar as influências e a natureza delas, nessa importante fase de socialização profissional. 


\section{Educational support in initial training: prospects for teaching well-being and professional development}

\section{Abstract}

From experiences of undergraduates and beginning teachers, the article highlights the pedagogical support in teacher training, in view of its relevance to professional formation and prospects for teaching well-being. The qualitative longitudinal study is the result of research conducted between 2012 and 2013, initially with sixty-eight potential future teachers of a private higher education institution in the State of Paraná, and finished with five beginner teachers with information collected through questionnaires and interviews, treated with content analysis. As a result of the training period in degree, stand out mainly relational insecurity, lack of support and interaction with those involved in the training process at school and the need for greater monitoring of teachers in teaching practice. In the beginning of teaching, there is evidence of the unstable relational climate between teachers, lack of cooperative environment between teachers and lack of pedagogical support to beginning teachers. It is suggested optimization and institutionalization of support to future teachers and novice teachers, as well as improvement of relations between institutions and individuals involved in this educational process.

Keywords: Initial training. Pedagogical support. Undergraduates. Teachers.

\section{Referências}

ANDRÉ, Marli; HOBOLT, Marcia de S. As Práticas de Licenciatura e o Trabalho Docente dos Formadores na Perspectiva de Licenciados de Letras. Educação em Perspectiva, Viçosa, v. 4, n. 1, p. 175- 198, jan./jun. 2013.

AZEVEDO, Maria A. R.; ANDRADE, Maria de F. R. Os professores formadores e os saberes de orientação mediante ações tutorais. Educação, Porto Alegre, v. 33, n. 3, p. 213-221, set./dez. 2010.

BARDIN, Laurence. Análise de conteúdo. 3. ed. Lisboa: Edições 70, 2010.

CAVACO, Maria H. Ofício do professor: o tempo e as mudanças. In NÓVOA, Antônio (ed.). Profissão Professor. Porto: Porto Editora, 1991. p. 155- 191.

ESTEVE, José M. O mal-estar docente. Lisboa: Escher, 1992.

O mal-estar docente. 3. ed. Barcelona: Paidós, 1994.

. Mudanças Sociais e Função Docente. In: NÓVOA, A. Profissão Professor. 2. ed. Portugal: Porto Editora, 1995.

FLORES, Maria Assunção. Reflexões em torna da formação inicial de professores. Educação, Porto Alegre, v. 33, n. 3, p. 182 - 188, set./dez. 2010. 
GRILLO, Marlene. O professor e a docência: o encontro com o alunos. In: ENRICONE, Délcia. Ser professor. Porto Alegre: EDIPUCRS, 2004.

HUBERMAN, M. Le cycle de vie profissionnelle des enseignants secondaires. Résumé d'une recherche démentielle. Genève: Cahiers de la Section des Sciences de l'Education (54), Université de Genève, 1989.

HUBERMAN, Martin. O ciclo de vida profissional dos professores. In: NÓVOA, A. (Org.) Vidas de professores. Porto: Porto Editora, 1995.

IMBERNÓN, Francisco. Formação docente e profissional: formar-se para a mudança e a incerteza. 9 ed. São Paulo: Cortez, 2011.

JESUS, Saul N. de. A motivação para a profissão docente: contributo para a clarificação de situações de mal-estar docente e para a fundamentação de estratégias de formação de professores. Aveiro: Estante Editora, 1996.

. Bem-estar dos professores: estratégias para realização e desenvolvimento profissional. Porto: Porto Editora, 1998.

. Perspectivas para o bem-estar docente. Porto: ASA Editores, 2002. ção, 2007.

Professor sem stress: realização profissional e bem-estar docente. Porto Alegre: Media-

Estudo do mal-estar docente segundo um modelo integrativo de teorias da motivação. In: SANTOS, Bettina S.; ANTUNES, Denise D.; BERNARDI, Jussara (Org.). Processos motivacionais em contextos educativos. Malgualde/Ramada: Edições Pedago, 2012.

JESUS, Saul Neves de; SANTOS, Joana. C. V. Desenvolvimento profissional dos professores. Educação - PUCRS, ano 26, v. 1, n. 52, p. 39- 58, jan./abr. 2004.

LÜDKE, M. Universidade, escola de educação básica e o problema do estágio na formação de professores. 2010. Disponível em: <http://formacaodocente.autenticaeditora.com.br/artigo/exibir/1/5/5>. Acesso em: 10 fev. 2014.

LÜDKE, Menga. O estágio e seu papel na socialização profissional de professores. In: REBOLO, Flavinês; TEIXEIRA, Leny R.; PERRELLI, Maria A. de S. (Org.) Docência em questão: discutindo trabalho e formação. Campinas: Mercado de Letras, 2012.

LÜDKE, M.; RODRIGUES, P. A. M. O estágio como porta de entrada para o trabalho docente. In: CORDEIRO, A. F. M.; HOBOLT, M. S.; AGUIAR, M. A. L. de (Org.). Trabalho docente, formação, práticas e pesquisa. Joinville: Univille, 2010. p. 29-46.

MIRA, Marília M.; ROMANOWSKI, Joana, P. A relação universidade-escola no estágio supervisionado do curso de pedagogia: desafios e possibilidades. EntreVer, Florianópolis, v. 2, n. 3, p. 184-199, jul./dez. 2012.

MIZUKAMI, Maria da Graça N.; NONO, Maévi Anabel. Processos de formação de professoras iniciantes. In: REUNIÃO ANUAL DA ASSOCIAÇÃO NACIONAL DE PESQUISA EM EDUCAÇÃO, 29, 2006, Caxambu, MG. Anais..., Caxambu, 2006. p. 1- 15.

MOSQUERA, Juan J. M.; STOBÄUS, Claus D. Educação para a saúde. 2. ed. Porto Alegre: D. C. Luzzatto, 1984. 
O mal-estar na docência: causas e consequências. Educação - PUCRS, a. 19, n. 31, p. 139-146, 1996.

34 , nov. 2000 .

O mal-estar na docência: causas e consequências. Revista da ADPPUCRS, n. 32, p. 23-

. O professor, personalidade saudável e relações interpessoais. In: ENRICONE, Délcia (Org.). Ser professor. 4. ed. Porto Alegre: EDIPUCRS, 2004. p. 91-107.

. Auto-imagem, auto-estima e realização: qualidade de vida na universidade. Psicologia, Saúde \& Doenças, v. 7, n. 1, p. 83-88, 2006.

NONO, Maévi A.; MIZUKAMI, Maria da G. N. Processos de formação de professoras iniciantes. Revista Brasileira de Estudos Pedagógicos, Brasília, v. 87, n. 217, p. 382- 400, set./dez. 2006.

NÓVOA, Antonio. Os professores e as histórias da sua vida. In: NÓVOA, António (org.). Vidas de Professores. Porto: Porto Editora, 1992.

. Formação de professores e trabalho pedagógico. Lisboa: Educa, 2002.

jan./jun. 2013.

Entrevista com Antonio Nóvoa. Educação em Perspectiva, Viçosa, v. 4, n. 1, p. 224-237,

NUNES, Maria L. T.; TEIXEIRA, Rita P. Burnout na carreira acadêmica. Educação - PUCRS, ano XXIII , n. 41, p. 147-164, 2000.

PACHECO, José A. Formação de Professores: Teoria e Praxis. Braga: IEP, 1995.

PAPI, Silmara de Oliveira. Professoras iniciantes bem-sucedidas: elementos de seu desenvolvimento profissional. In: REUNIÃO ANUAL DA ASSOCIAÇÃO NACIONAL DE PESQUISA EM EDUCAÇÃO, 34., 2011, Natal, RN. Anais... Natal, 2011. p. 1-16.

ROLDÃO, Maria do C. Função docente: natureza e construção do conhecimento profissional. Revista Brasileira de Educação, Rio de Janeiro, v. 12, n. 34, p. 94-103, 2007.

SAMPAIO, Adelar A. Vivências de docentes e de seus licenciandos no final de formação e passagem para o mundo do trabalho: mal/bem-estar docente/discente, autoimagem e autoestima. 2014. Tese (Doutorado em Educação) - Pontifícia Universidade Católica do Rio Grande do Sul, Porto Alegre, 2014.

RAMIREZ, Vera; STOBÄUS, Claus. Profissionalismo Docente e a Docência na Educação Superior. In: CELL - CONGRESSO LASALLISTA DE EDUCAÇÃO, 2010, Niterói, RJ. Anais... Niterói, RJ, 2010, p. 1-16.

TARDIF, Maurice. Saberes docentes e formação profissional. Petrópolis, RJ: Vozes, 2002.

VEENMAN, Simon. El proceso de llegar a ser profesor: un análisis de la formación inicial. In: VILLA, Aurelio (Coord.). Perspectivas y problemas de la función docente. Madrid: Narcea, 1988. p. 39-68.

ZABALZA, Miguel A. O ensino Universitário: seu cenário e seus protagonistas. Porto Alegre: Artmed, 2004. 